Received: 02-02-2021

(Date-Month-Year)
Revised: 05-04-2021

(Date-Month-Year)
Published: 30-04-2021

(Date-Month-Year)

\title{
ANALISIS KEMAMPUAN BERPIKIR KREATIF MATEMATIS PESERTA DIDIK DALAM DISCOVERY LINK MAP
}

\author{
Atmi Setiasari $^{1}$, Retno Marsitin ${ }^{2}$, Trija Fayeldi ${ }^{3}$ \\ 1,2,3 Pendidikan Matematika, Universitas Kanjuruhan Malang, Indonesia \\ 1'atmi.setiasari98@gmail.com \\ ${ }^{2}$ mars retno@unikama.ac.id \\ trija_fayeldi@unikama.ac.id
}

\begin{abstract}
Abstrak: Kecakapan peserta didik dalam mengungkapkan banyak ide saat merampungkan permasalahan matematika dinamakan dengan berpikir kreatif matematis. Tingkat kemampuan berpikir kreatif merupakan kriteria untuk memahami dan menganalisis kreativitas peserta didik. Maksud studi ini ialah guna mengklasifikasikan kecakapan berpikir kreatif peserta didik dengan model discovery link map. Studi ini memakai pendekatan kualitatif, dengan jenis Studi deskriptif-kualitatif. Subjek Studi terdiri atas 19 peserta didik kelas VIIA SMP PGRI 6 Malang, kemudian diambil 6 peserta didik untuk dianalisis, karena terdapat kesamaan jawaban di setiap tingkatannya. Akumulasi nilai diperoleh dari tes, wawancara, dan dokumentasi. Uji kebenaran data diperoleh dari teknik triangulasi metode. Nilai dianalisa melalui langkah pengurangan data, presentasi data dan penarikan kesimpulan. Hasil studi antara lain, Pada aspek kelancaran, peserta didik tergolong pada kriteria cukup kreatif dengan persentase $63,15 \%$, pada aspek keluwesan, peserta didik tergolong pada kriteria kreatif dengan persentase $73,68 \%$, dan pada aspek keaslian, peserta didik tergolong pada kriteria tidak kreatif dengan persentase $0 \%$. Kesimpulan berdasarkan hasil studi diperoleh kesanggupan berpikir kreatif matematis peserta didik pada aspek kelancaran tergolong kriteria cukup kreatif. Aspek keluwesan tergolong kriteria kreatif. Aspek keaslian tergolong kriteria tidak kreatif.
\end{abstract}

Kata Kunci: Discovery Link Map, Kemampuan berpikir kreatif matematis.

\begin{abstract}
The ability of students to express many ideas when solving mathematical problems is called mathematical creative thinking. The level of creative thinking ability is a criterion for understanding and analyzing the creativity of students. The purpose of this study is to classify students' creative thinking skills with a discovery link map model. This study uses a qualitative approach, with a descriptive-qualitative research type. The research subjects consisted of 19 students of class VIIA SMP PGRI 6 Malang, then 6 students were taken to be analyzed, because there were similarities in answers at each level. Accumulated scores were obtained from tests, interviews, and documentation. Test the correctness of the data obtained from the method triangulation technique. Values are analyzed through data reduction steps, data presentation and drawing conclusions. The results of the study included, in the fluency aspect, students were classified as quite creative with a percentage of $63.15 \%$, in the flexibility aspect, students belonged to the creative criteria with a percentage of $73.68 \%$, and in the aspect of authenticity, students belonged to the criteria. not creative with a percentage of $0 \%$. The conclusion based on the results of the study showed that students' mathematical creative thinking abilities in the fluency aspect were classified as quite creative criteria. The flexibility aspect is classified as a creative criterion. The aspect of authenticity is classified as uncreative criteria.
\end{abstract}

Keyword: Discovery Link Map, Mathematical creative thinking skills. 


\section{Pendahuluan}

Pembelajaran matematika adalah suatu pembelajaran dengan cara pemberian stimulus oleh guru kepada peserta didik. Kebebasan penyelesaian masalah akan menambah kemampuan berpikir kreatif peserta didik (Ariyanti, 2017:2). Pembelajaran matematika merupakan pembelajaran yang bertujuan supaya peserta didik mampu mengembangkan kreativitas dalam memecahkan masalah matematika, memahami konsep, dan penalaran matematika (Kurniawati, 2017:174).

Model pembelajaran merupakan tampilan secara grafis, langkah kerja yang teratur atau sistematis. Model pembelajaran berisi tentang pikiran secara deskriptif mengenai penyajian suatu pembelajaran yang berdasarkan teori-teori, antara lain teori belajar, pembelajaran, psikologi, sistem, dan sebagainya (Marliani, 2015:21). Model pembelajaran digunakan untuk meningkatkan antusias dalam mengutarakan hasil pemikirannya. Rachmayani (2014:15) berpendapat jika model pembelajaran matematika yang sesuai sanggup mengamalkan trik matematika di kegiatan nyata.

Model pembelajaran matematika bertujuan membantu peserta didik memahami konsep, menyelesaikan suatu masalah, dan menerapkan masalah matematika dalam kehidupan nyata. Salah satu model pembelajaran matematika adalah pembelajaran discovery. Menurut Muhamad (2016:12) model discovery learning merupakan pembelajaran yang tidak berisi konsep berbentuk final. Pembelajaran discovery adalah pembelajaran dengan cara guru membuat kelompok kecil antar peserta didik serta membimbing mereka untuk menemukan suatu konsep matematika. Tahapan dalam pembelajaran discovery antara lain stimulasi, penyelesaian masalah, mengoleksi data, memproses data, verivikasi, generalisasi (Kurniadi dan Purwaningrum, 2018:10).

Lindstrøm and Sharma (dalam Marsitin dan Sesanti, 2018:274-275) menjelaskan bahwa Link map merupakan suatu pembelajaran dengan materi yang disajikan secara berhubungan satu sama lain yang selanjutnya dikemas menjadi peta kerterkaitan (link map) sehingga tidak sulit dimengerti siswa. Junedi dan Chandra (2018:91) mengemukakan bahwa peta keterkaitan mempermudah mengerti dan menguasai materi sejak awal berdasarkan sifat matematika yang hirearki yaitu harus menguasai konsep sebelumnya untuk memahami konsep yang selanjutnya. Dapat disimpulkan bahwa, discovery link map digunakan sebagai pemahaman matematika secara lebih nyata dengan cara pembentukan peta keterkaitan materi.

Peserta didik ketika diberikan pembelajaran berbasis masalah, tingkat kepekaan mereka untuk berpikir akan lebih tinggi dibanding dengan peserta didik yang hanya mengacu pada contoh yang diberikan oleh guru (Ariyanti, 2017:2). Kreativitas merupakan kemampuan daya cipta seseorang dalam merealisasikan ide-ide yang ada pada pemikirannya sehingga mampu menciptakan sesuatu yang baru (Marliani, 2015:17). Peserta didik yang kreatif mampu menggunakan cara mereka sendiri atau gabungan dari cara yang pernah diajarkan untuk menyelesaikan suatu masalah matematika. Hanipah dkk (2018:80) berpendapat bahwa berpikir kreatif adalah kemampuan hidup yang dibutuhkan untuk menghadapi ilmu pengetahuan dan teknologi.

Berdasarkan observasi peneliti dengan guru matematika SMP PGRI 6 Malang, peserta didik menyelesaikan masalah matematika hanya berpedoman 
pada pendidik. Berpedoman pada hasil ujian, mereka berhasil mencapai KKM yaitu 60 sebanyak 55\%, sedangkan sebanyak $45 \%$ masih di bawah KKM. Perlu adanya cara mengajar lebih nyata yang selanjutnya mereka bisa merampungkan masalah matematika dengan cara mereka sendiri.

Kemampuan berpikir kreatif matematis merupakan kemampuan yang membutuhkan suatu keterampilan saat merampungkan permasalan matematika. Model pembelajaran discovery link map adalah model yang sesuai untuk melatih kecakapan matematis siswa. Berdasarkan tersebut, studi ini memakai model discovery berbasis link map guna mengidentifikasi kecakapan matematika siswa.

\section{Metode Studi}

\begin{tabular}{lrr}
\multicolumn{1}{c}{ Studi ini merupakan } & deskriptif- \\
kualitatif, & bermaksud & untuk \\
mengemukakan & peristiwa & secara
\end{tabular} kualitatif dan berdasar data kualitatif. Studi ini dilakukan untuk melakukan analisis terhadap kemampuan berpikir kreatif matematis peserta didik kelas VII SMP PGRI 6 Malang. Peneliti sebagai perencana, pelaksana, pengendali, pengumpul dan penganalisis data, penarik kesimpulan dan pembuat laporan. Studi ini dilasanakan di SMP PGRI 6 Malang yang terletak di Jl. Kolonel Sugiono 8 No.82 Ciptomulyo, Sukun, kota Malang. Subjek dalam Studi ini yaitu peserta didik kelas VII SMP PGRI 6 Malang tahun ajaran 2019/2020. Peneliti akan mengelompokkan peserta didik berdasarkan kriteria persentase skor berpikir kreatif.

Prosedur akumulasi data yang dilakukan dalam studi ini adalah tes kemampuan berpikir kreatif matematis peserta didik, Wawancara dipilih karena dapat mengawasi pendapat peserta didik dengan semakin valid dan melihat timbal balik sikap peserta didik dari soal yang diajukan dan validasi dipakai sebagai memvalidasi soal tes kemampuan berpikir kreatif matematis dan RPP dengan model discovery link map. Analisis data terdiri dari perekdusian data, penyajian data dan penarikan kesimpulan. Pengecekan keabsahan data menggunakan triangulasi metode. Pada tahap perencanaan peneliti membuat RPP dengan model discovery berbasis link map dan tes tertulis berbentuk soal-soal bab perbandingan senilai dan pedoman wawancara yang disusun berdasarkan permasalahan yang dihadapi subjek. RPP dan tes tertulis disusun dan ajukan kepada dosen pembimbing kemudian di validasi oleh dua validator. Pada tahap pelaksanaan peneliti melaksanakan Studi dengan menyampaikan bab persamaan dan pertidaksamaan linear satu variabel, kemudian memberikan tes kemampuan berpikir kreatif dan wawancara berdasarkan kriteria tingkat kemampuan berpikir kreatif matematis yang dimiliki oleh peserta didk. Pada tahap analisis data peneliti mengumpulkan dan menganalisis data secara langsung dari subjek berupa tes tertulis dan wawancara.

\section{Hasil dan Pembahasan}

Berikut hasil jawaban peserta didik sesuai kemampuan berpikir kreatif matematis.

1. Hasil jawaban siswa dengan kategori cukup kreatif

Pi: Mathematics Education Journal

http://ejournal.unikama.ac.id/index.php/pionly/index 


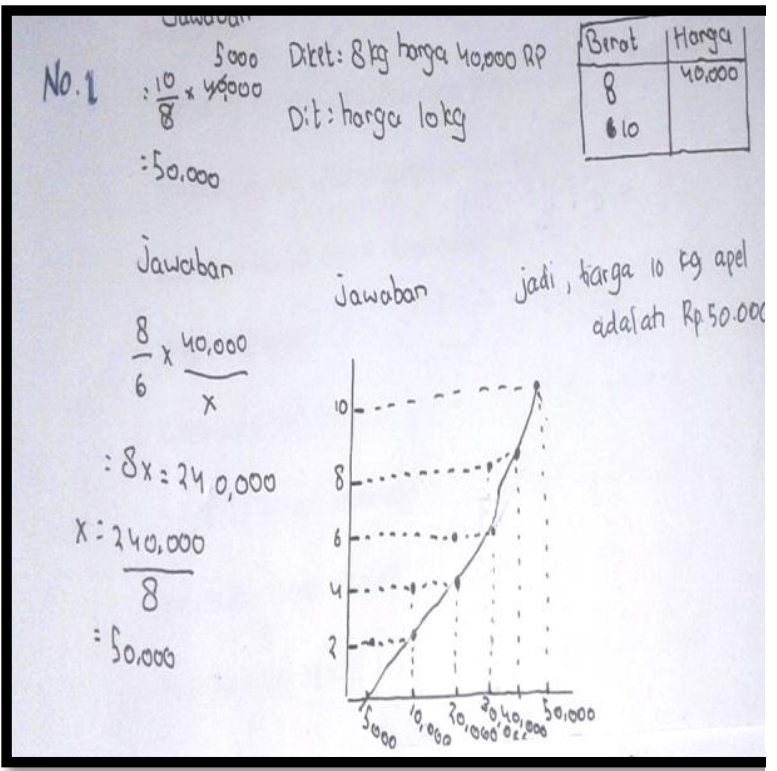

Gambar 1. Hasil jawaban HS dengan kategori cukup kreatif

Hasil pengerjaan soal tes kemampuan berpikir kreatif oleh subjek HS menunjukkan bahwa subjek HS mampu mengerjakan soal dengan skor kelancaran (fluency) $=4$, skor keluwesan (flexibility) $=4$, dan skor keaslian (originality) $=0$. Begitu juga dengan hasil wawancara dengan subjek HS yang menunjukkan mampu mengerjakan soal dengan dua cara atau metode, yaitu grafik dan persamaan dengan perhitungan dan hasil yang benar, namun belum menunjukkan keaslian. Subjek HS mewakili tingkatan cukup kreatif atau TKBK 2.

2. Hasil jawaban siswa dengan kategori kurang kreatif

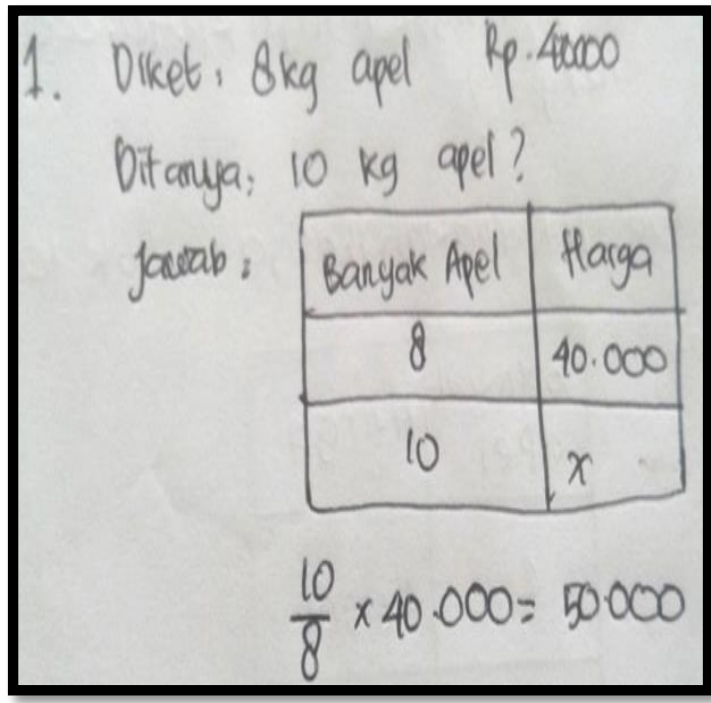

Gambar 2. Hasil jawaban SR dengan kategori kurang kreatif

Hasil pengerjaan soal tes kemampuan berpikir kreatif oleh subjek SR menunjukkan bahwa subjek SR mampu mengerjakan soal dengan dengan skor kelancaran (fluency) $=2$, skor keluwesan (flexibility) $=4$, dan skor keaslian $($ originality $)=0$. Begitu juga dengan hasil wawancara dengan subjek SR yang menunjukkan mampu mengerjakan soal dengan 1 cara atau metode, yaitu tabel dengan perhitungan dan hasil yang benar, namun belum menunjukkan keaslian. Subjek SR mewakili tingkatan kurang kreatif atau TKBK 1.

3. Hasil jawaban siswa dengan kategori tidak kreatif 


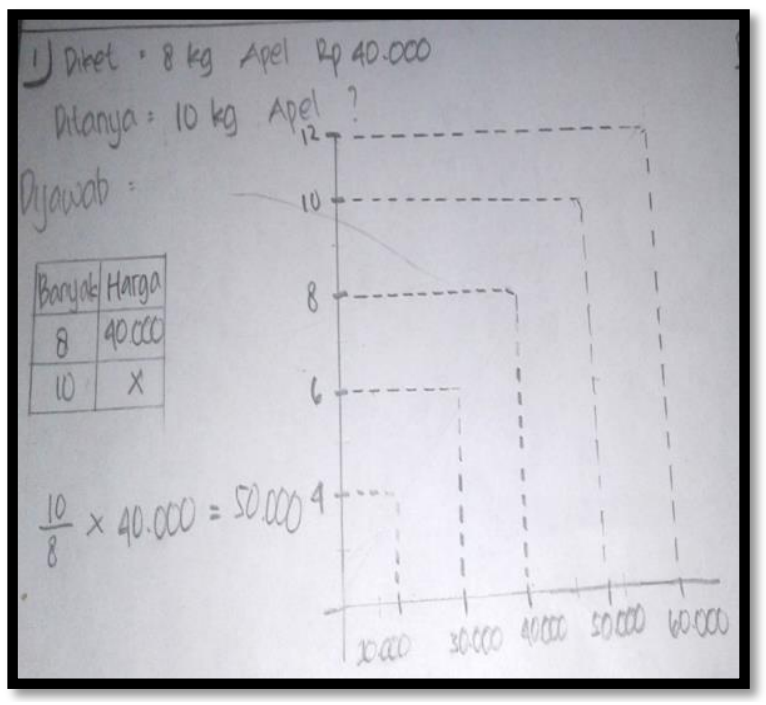

Gambar 3. Hasil jawaban NAN dengan kategori tidak kreatif

Hasil pengerjaan soal tes kemampuan berpikir kreatif oleh subjek NAN menunjukkan bahwa subjek NAN mengerjakan soal dengan dengan skor kelancaran (fluency) $=4$, skor keluwesan (flexibility) $=4$, dan skor keaslian (originality) $=0$. Namun hasil wawancara dengan subjek NAN menunjukkan bahwa sebenarnya mampu mengerjakan soal nomor 3 dan 3 akan tetapi kurang adanya kemauan dan ketekunan. Subjek NAN mewakili tingkatan tidak kreatif atau TKBK 0.

\section{Kesimpulan}

1. Tingkat Kemampuan Berpikir Kreatif (TKBK) peserta didik tersebar pada TKBK 0 atau tidak kreatif, TKBK 1 atau kurang kreatif, dan TKBK 2 atau cukup kreatif. Pada TKBK 0 atau tidak kreatif tedapat 6 subjek, pada TKBK 1 atau kurang kreatif terdapat 5 subjek, dan pada TKBK 2 atau cukup kreatif terdapat 8 subjek.

2. Discovery Link Map dapat meningkatkan hasil nilai peserta didik, diperoleh sebanyak 15 orang atau $79 \%$ telah memenuhi KKM dan 4 orang atau $21 \%$ belum memenuhi KKM.
Saran dari peneliti yaitu guru harus memahami tingkat kemampuan berpikir kreatif matematis siswa agar mampu melaksanakan edukasi yang efektif. Guru diharuskan menerapkan model edukasi yang bisa menggali pemahaman siswa dapat memahami materi. Salah satunya yaitu model discovery link map. Studi ini hanya berfokus pada 5 tingkat kemampuan berpikir kreatif dan 3 aspek kemampuan berpikir kreatif oleh karena ini peneliti selanjutnya dapat mengembangkan lagi menjadi beberapa tingkatan yang lebih spesifik dengan keampuan berpikir kreatif matematis peserta didik sehingga perlu dilakukan Studi lebih lanjut dari peneliti lain agar dapat lebih memantapkan hasil kemampuan berpikir kreatif matematis peserta didik.

\section{Daftar Rujukan}

Ariyanti, S. 2017. Analisis Kemampuan Berpikir Kreatif Matematis Siswa Kelas VII SMP Negeri 7 Kediri pada Materi Segi Empat. Simki-Techsain. 01(02):2.

Fajriah, N., \& Asiskawati, E. 2015. Kemampuan Berpikir Kreatif Siswa dalam Pembelajaran Matematika menggunakan Pendekatan Pendidikan Matematika Realistik di SMP. EDU-MAT Jurnal Pendidikan Matematika. 03(02):159.

Hanipah, N. dkk. 2018. Analisis Kemampuan Berpikir Kreatif Matematis Siswa Mts Pada Materi Lingkaran. AKSIOMA: Jurnal Program Studi Matematika. 07(01):80-86.

Junedi, B., \& Chandra, R.A. 2018. Penggunaan Model Pembelajaran Concept Mapping terhadap Pemahaman Konsep Matematika 
Siswa Kelas VII. PROCEEDING IAIN Batusangkar. 03(02):91.

Kurniadi, G., \& Purwaningrum, J.P. 2018. Kemampuan Pemahaman Matematis Siswa Melalui Discovery Learning Berbantuan Asesmen Hands on Activities. Anargya: Jurnal Pendidikan Matematika. 01(01):10.

Kurniawati, E. dkk. 2017. Pengaruh Model Pembelajaran Assurance, Relevance, Interest, Assesment, Satisfaction (Arias) Integratif dan Kemampuan Awal dalam Meningkatkan Pemahaman Konsep dan Pemecahan Masalah Matematika Siswa Sekolah Menengah Pertama Di Kepahiang. Jurnal Pendidikan Matematika Raflesia. 02(02): 174.

Lestari, N., \& Zanthy, L.S. 2019. Analisis Kemampuan Berpikir Kreatif Matematis Siswa SMK di Kota Cimahi pada Materi Geometri Ruang. JPMI: Jurnal Pendidikan Matematika Inovatif. 02(04):10.

Marliani, N. 2015. Peningkatan Kemampuan Berpikir Kreatif Matematis Siswa Melalui Model Pembelajaran Missouri Mathematics Project (MMP). Jurnal Formatif. 05(01):14-25.

Marsitin, R., \& Sesanti, N.R. 2018. Pembelajaran Discovery dan Link Map terhadap Koneksi Matematik. Conference on Innovation and Application of Science and Technology (CIASTECH 2018). 274.

Muhamad, N. 2016. Pengaruh Metode Discovery Learning untuk Meningkatkan Representasi Matematis dan Percaya Diri Siswa. Jurnal Pendidikan Universitas Garut. 09(01):12.
Putri, C.A. 2019. Kemampuan Berpikir Kreatif Matematis Siswa melalui Model Pembelajaran Brain-Based Learning. Jurnal Didaktik Matematika. 06(01):15.

Rachmayani, D. 2014. Penerapan Pembelajaran Reciprocal Teaching

Untuk Meningkatkan Kemampuan Komunikasi Matematis dan Kemandirian Belajar Matematika Siswa. JUDIKA (Jurnal Pendidikan Unsika). 02(01):15.

Rahayu, E.L., dkk. 2018. Pengaruh Metode Mind Mapping terhadap Strategi

Thinking Aloud Pair Problem Solving terhadap Kemampuan Berpikir Kreatif Matematis. Journal On Education. 01(02):272.

Rudyanto, H.E. 2014. Model Discovery Learning dengan Pendekatan Saintifik Bermuatan Karakter untuk Meningkatkan Kemampuan Berpikir Kreatif. Premiere Educandum. 04(01):43-48.

Widiningtyas, A. 2018. Analisis Kemampuan Menyelesaikan Masalah pada Materi Rangkaian Arus Searah Berdasarkan Polya pada Siswa Kelas XII IPA 4 SMA Negeri 4 Jember. Seminar Nasional Pendidikan Fisika 2018. 04(01):270.

Pi: Mathematics Education Journal 